\title{
SYSTEMATIC LITERATURE REVIEW OF MY HEALTH RECORD SYSTEM
}

\author{
Rafael Carneiro de Mesquita, Ian Edwards \\ Griffith University - Health Service Management, Queensland, Australia
}

Correspondence: rafael.carneirodemesquita@griffithuni.edu.au

\begin{abstract}
\section{BACKGROUND}

On 2010 Australia launched a personally controlled electronic health record (PCEHR) later renamed and augmented by the My Health Record Act 2012 Cth. The main goal of the present systematic literature review was to assess if the system has improved Australia's healthcare system according to the objectives stated by the federal government in the My Health Record Act 2012 Cth.

METHODS
\end{abstract}

The methodological approach taken in this study was a Systematic Review based on nine peer-reviewed articles of the last five years using the Preferred Reporting Items for Systematic Reviews and Meta-Analysis (PRISMA).

\section{RESULTS}

Despite the MyHR system being available for seven years, there is limited empirical evaluation regarding its progress in achieving the stated goals. The results were segregated in four themes: (1) health information fragmentation, (2) Health information quality and management, (3) adverse medical events and duplication of treatment and (4) coordination of care. Regarding theme 1, it was evidenced that the system could reduce health information fragmentation; however, gaps in the workforce adoption were identified as a problem. About topic 2, improved access to information and possible misinterpretation were found. Theme 3 lacked research and theme 4 presented contradiction in the results.

\section{CONCLUSION}

The My Health Record (MyHR) system is founded on four key objectives. However, there is insufficient evidence that any outcomes have been achieved relating to any of the objectives. Research is required to determine whether the MyHR system helped improve Australia's healthcare system according to the objectives stated in the Act 2012.

\section{KEYWORDS}

My Health Record, MyHR, personally controlled electronic health record, PCEHR, Act 2012

\section{INTRODUCTION}

The Personally Controlled Electronic Health Record (PCEHR) system was introduced in Australia in May 2010 by the Minister of Health and Ageing, Nicola Roxon, who allocated AU $\$ 466.7$ million for the project; this figure has since risen to AU $\$ 2$ billion as at 2016.[1, 2] The expected net benefit was estimated in AU\$ 11.5 billion over 2010-25.[3] In 2012 the system was launched as a shared database where patients' information could be stored and accessed online. The system provides the healthcare workforce with a tool to amalgamate information about medications, adverse drug reactions, allergies and immunisation history to be used in better clinical decision-making.[4] The underlying concept of the system is that it would improve patient safety and healthcare delivery and reduce waste and duplication.[1]

In 2016 the system was renamed My Health Record (MyHR) and significant legislative changes referring to the privacy of the data were undertaken. However, despite the government's efforts in building a secure and reliable 
system, it has not been widely accepted by the population. [5] Due to slow acceptance by the Australian public and the relatively low number of general practitioners (GPs) using the system (less than $10 \%$ of the $80 \%$ of GPs registered as at 2013) [6], it was changed from opt-in to opt-out in January 2019. This alteration resulted in 9.9\% of eligible people in Australia voicing their decision to opt-out.[7] Although concerns remain regarding the privacy and security of information[8,9], research in 2017 indicated a positive result about individuals' health information availability across health providers.[5, 10] In relation to the government objectives, it is time to identify what has been achieved since the launch of the MyHR system. The objectives of the system were defined in the My Health Records Act 2012 (Cth) (hereafter known as the Act 2012) by the Australian government as follows:

The object of this Act is to enable the establishment and operation of a voluntary national system for the provision of access to health information relating to recipients of healthcare, to:

- 1. Help overcome the fragmentation of health information; and

- 2. Improve the availability and quality of health information; and

- 3. Reduce the occurrence of adverse medical events and the duplication of treatment; and

- 4. Improve the coordination and quality of healthcare provided to healthcare recipients by different healthcare providers.[11] (Part 1, Section 3, page 2)

This paper has been divided into four sections. The first section is this introduction. The second section deals with the methods used for this paper; the third section presents the results of the articles reviewed, focusing on the four key themes - health information fragmentation, health information quality and access, adverse medical events and duplication of treatment and coordination of care, which corresponds to each of the Act 2012 objectives. The fourth section discusses the results. The findings should make a relevant contribution to the community by presenting the current progress of the objectives stated by the government and indicating questions that required research.

\section{QUESTION}

Have the My Health Record system objectives stated in the Act 2012 been accomplished, therefore improving Australia's healthcare system?

In this systematic literature review, improvement of Australia's healthcare system is defined as better access to and better quality of health information, less health information fragmentation, less duplication of treatment and occurrence of medical events and better management of care.

\section{SCOPE}

The scope of this paper was to assess if the MyHR system succeeded in its proposed objectives. These objectives are to:

- 1. Help overcome the fragmentation of health information.

- 2. Improve the availability and quality of health information.

- 3. Reduce the occurrence of adverse medical events and the duplication of treatment.

- 4. Improve the coordination and quality of healthcare provided to healthcare recipients by different healthcare providers.

\section{METHODOLOGY}

The present systematic literature review of the scientific literature was based on the Preferred Reporting Items for Systematic Reviews and Meta-Analyses (PRISMA)[12]. The peer-reviewed articles were located using five high-ranked health-related electronic databases. The databases were selected considering their scope of knowledge (medical, biomedical and multidisciplinary) and region (American, European and International), as listed in Table 1.

The search was conducted using each database website and search engine. The search string contained the following words and Boolean operators: "My Health Record" OR MYHR OR "personally controlled electronic health record" OR PCEHR. The author decided to not use the Boolean operators "AND" and "NOT", which would restrict the number of results, because it was already short due to the topicality - 150 papers over the five databases. The words used correspond to this paper's objective of study. To be included in this search, the article title or abstract needed to contain the words presented. 


\begin{tabular}{|l|l|l|}
\hline DATABASE & DISCIPLINE & REGION \\
\hline Embase & Biomedical & European \\
\hline Medline & Medical & American \\
\hline ProQuest & Multidisciplinary & International \\
\hline PubMed & Biomedical & American \\
\hline Scopus & Multidisciplinary & International \\
\hline
\end{tabular}

Listed in Table 2 are the inclusion and exclusion criteria that focused on (1) identifying articles corresponding to the Australian personally controlled electronic health record system, (2) studies about the system and not clinical data, which includes but are not limited to legal aspects and analysis of the system and people's experiences and (3) studies that are relevant in time, because technological features tend to change constantly. Research about the users' expectations and possible barriers were excluded because the purpose of this work is to identify the current situation. Implementation of the system, adoption rate and improvement suggestions were also excluded. The author acknowledges the importance of these topics and their influence on the objectives studied in this work. However, a standalone analysis of each topic is appropriate. Further, duplications were removed and titles and abstracts were screened by the author.
Additional analysis of the paper selection process applied the Standard Quality Assessment Score (SQAS) [13] qualitative for primary research papers. The scoring system was developed to evaluate the quality of primary research papers from different fields and contains ten questions (see Table 3). For the evaluation of the literature review papers, the author used the Quality Assessment Tool (QAT).[14] This evaluation system was specifically developed for the healthcare area, and contains ten questions (see Table 4). The SQAS and the QAT require the division of the papers' score for the maximum score possible and present the results in decimal numbering; the closer the number to one (1), the better the results, with one being the maximum.

Regarding the evaluation of the four objectives, there were no practical constraints. There was no need to appraise each individually because the number of articles found about the topic was modest. Few studies have investigated the topic due to it being so contemporary.

TABLE 2. INCLUSION AND EXCLUSION CRITERIA USED TO SCREEN IDENTIFIED ARTICLES

\begin{tabular}{|l|l|}
\hline INCLUSION CRITERIA & EXCLUSION CRITERIA \\
\hline $\begin{array}{l}\text { Articles published between January } 2014 \text { and } \\
\text { April } 2019\end{array}$ & $\begin{array}{l}\text { Electronic personal health record system other } \\
\text { than the Australian My Health Record }\end{array}$ \\
\hline Articles and Reviews & Clinical data \\
\hline Peer-reviewed/Refereed journals & Potential benefits \\
\hline Articles published in English & Barriers to potential use \\
\hline Australia & Improvement suggestions \\
\hline
\end{tabular}


TABLE 3. STANDARD QUALITY ASSESSMENT SCORE FOR QUALITATIVE PRIMARY RESEARCH PAPERS

\begin{tabular}{|ll|l|}
\hline CRITERIA & YES & PARTIAL NO \\
\hline 1 & Question/objective sufficiently described? & (1) \\
2 & Study design evident and appropriate? \\
3 & Context for the study clear? \\
4 & Connection to a theoretical framework/wider body of knowledge? & \\
5 & Sampling strategy described, relevant and justified? \\
6 & Data collection methods clearly described and systematic? \\
7 & Data analysis clearly described and systematic? \\
8 & Use of verification procedure(s) to establish credibility? \\
10 & Reflexivity of the account?
\end{tabular}

Source: Kmet et al.[13]

TABLE 4. QUALITY ASSESSMENT TOOL - REVIEW ARTICLES

CRITERIA

1

Did the authors have a clearly focused question [population, intervention

(strategy), and outcome(s)]?

2 Were appropriate inclusion criteria used to select primary studies?

Did the authors describe a search strategy that was comprehensive?

Circle all strategies used:

health databases handsearching

3 psychological databases key informants

social science databases reference lists

educational databases unpublished

other

4 Did search strategy cover an adequate number of years?

Did the authors describe the level of evidence in the primary studies included in

5 the review?

Level I $\rightarrow$ RCTs only 
Level II $\rightarrow$ non-randomized, cohort, case-control

Level III $\rightarrow$ uncontrolled studies

Did the review assess the methodological quality of the primary studies,

including:

(Minimum requirement: $4 / 7$ of the following)

Research design

Study sample

6

Participation rates

Sources of bias (confounders, respondent bias)

Data collection (measurement of independent/dependent variables)

Follow-up/attrition rates

Data analysis

7 Are the results of the review transparent?

8 Was it appropriate to combine the findings of results across studies?

9 Were appropriate methods used for combining or comparing results across

studies?

10 Do the data support the author's interpretation?

Source: Health Evidence[14]

\section{RESULTS}

The search for peer-reviewed articles was conducted according to the PRISMA methodology, and the results are illustrated in Figure 1. After searching in five selected databases, 150 articles were retrieved. All articles were combined in EndNote X8 and duplications were removed, with 105 papers remaining. Subsequently, titles were screened, and 58 appeared to be relevant to this work.

Further examination of the abstracts eliminated 28 pieces of research, and full-text assessment eliminated a further 21. Another eleven articles were manually located by browsing titles in the reference list of the nine remaining articles; however, after consultation on EndNote X8, it was concluded that they had been already screened and removed in earlier parts of the process. No quantitative study was found after the full-text screening. The inclusion and exclusion criteria were applied at all levels of this methodology.

Table 5 summarises the number of evidence-based articles for each database per process assessed in this study. It is observed that PubMed and Scopus retrieved a considerable number of papers, but after the screening process, few were compatible with the inclusion and exclusion criteria delimited by the scope of this work.

The four established themes identified by the author are intrinsically linked to the objectives established in the Act 2012. Table 6 organises the articles by theme and author. It is noteworthy that more than one author can be found in different themes. The main findings of each research study are summarised in Table 7 and discussed in the following section - the Discussion. In Table 7, the score calculated through the SQAS and SQT methodology is also shown for each paper. The score results perform an important role in the discussion section when comparing articles 

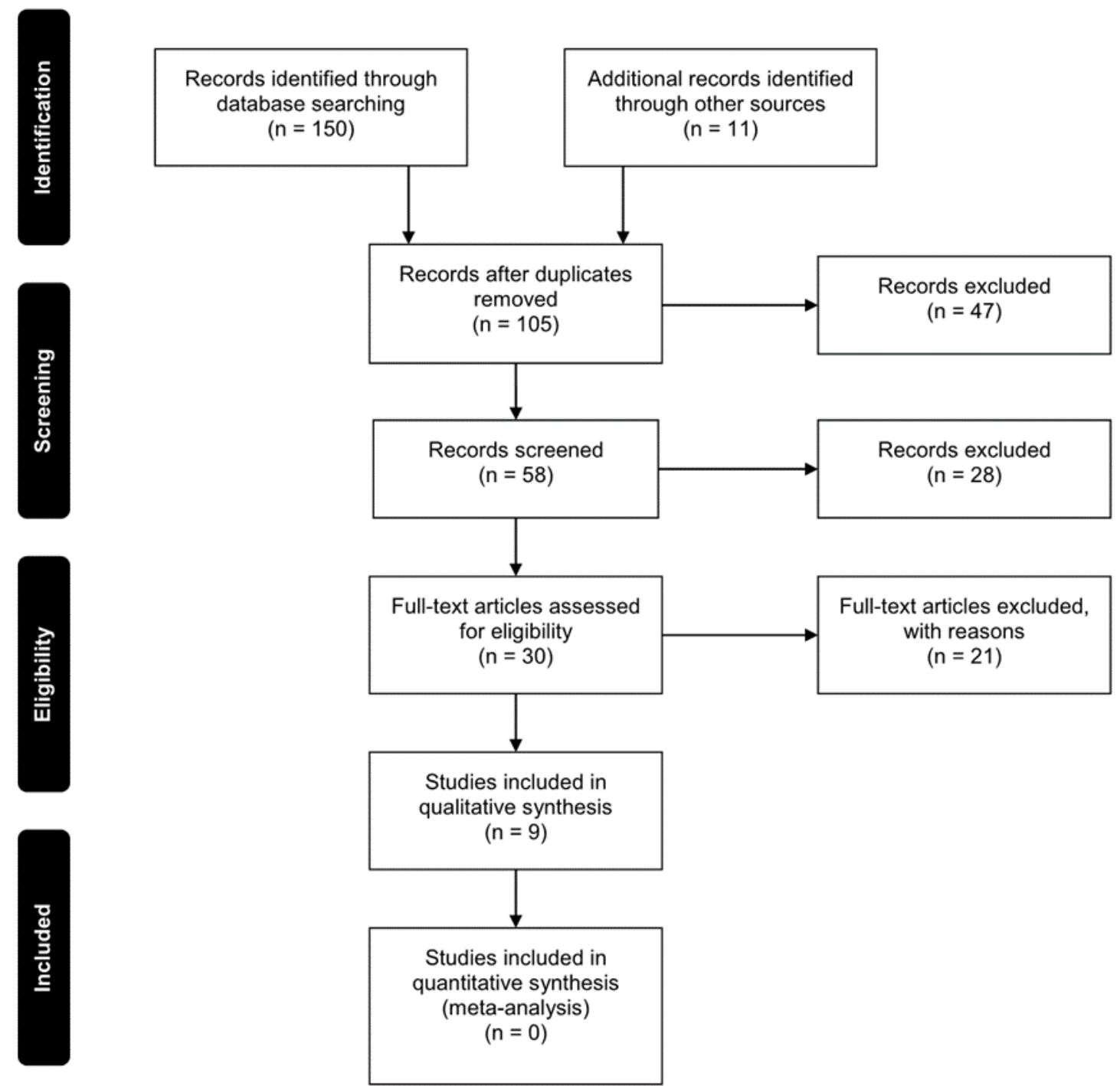

Source: Kmet et al. [13]

\section{TABLE 6. RESULTS OF ARTICLES BY THEMES AND AUTHORS}

\begin{tabular}{|c|c|c|}
\hline THEME & NO. ARTICLES & AUTHOR \\
\hline Health information fragmentation & 3 & $\begin{array}{l}\text { Hemsley et al. [8] Kariotis et al. } \\
\text { [15] Mendelson et al. [16] }\end{array}$ \\
\hline Health information quality and access & 7 & $\begin{array}{l}\text { Hanna et al. [10] Hemsley et al. } \\
\text { [8] Hemsley et al. [17] Kariotis et } \\
\text { al. [15] Mendelson et al. [16] } \\
\text { Pearce et al. [18] Walsh et al. } \\
\text { [19] }\end{array}$ \\
\hline $\begin{array}{l}\text { Adverse medical event and duplication of } \\
\text { treatment }\end{array}$ & 2 & $\begin{array}{l}\text { Hanna et al. [10] Kariotis et al. } \\
\text { [15] }\end{array}$ \\
\hline \multirow[t]{2}{*}{ Coordination of care } & \multirow[t]{2}{*}{4} & $\begin{array}{l}\text { Almond et al. [20] Hanna et al. } \\
\text { [10] Van Kasteren et al. [21] }\end{array}$ \\
\hline & & Walsh et al. [19] \\
\hline
\end{tabular}




\section{AUTHOR YEAR THEME METHODOLOGY}

Almond et $2017 \quad 4$
al. [20]
Qualitative study with 21 The key topics found were (1) MyHR is participants with two or more complex chronic diseases (CCC) recruited from three Australian rural areas. Data were collected at three different time points in 2015 : pre-adoption, adoption and postadoption of MyHR. Interviews were conducted in phases one and three and group sessions were held in phase three.

Hanna et 2017 2,3,4 Qualitative descriptive study used
al. [10]

semi-structured individual interviews from twelve patients of Barwon Health (regional health service in Australia) to identify the patient's perspective about MyHR. an enabler of equitable, personcentred and integrated healthcare for people with CCC, and (2) MyHR can be an access point to more extensive healthcare provision.
The study found that $50 \%$ (6) of 0.94 patients were active users of MyHR; the remaining $50 \%$ were registered but not using it. The main findings reflected on (1) improved quality of care through improved communication, patients perceived advantages in having one single repository of accurate information, which removes patient recall bias and unnecessary investigations or appointments. It also enables better decision-making, especially in first GP or specialist consultations or emergency events. Also, the findings reflected on (2) increased patient autonomy, which translates into the possibility to better coordinate care with or without health providers.

In one study, a young adult with severe cerebral palsy and severe communication impairment, and using a wheelchair, was asked to retrieve her health records at home. To accomplish the task, she required the help of her carer. However, she was able to access the digital medical records with the assistance of assistive technologies. Therefore, the finding suggests that MyHR could benefit people with severe communication impairment. 


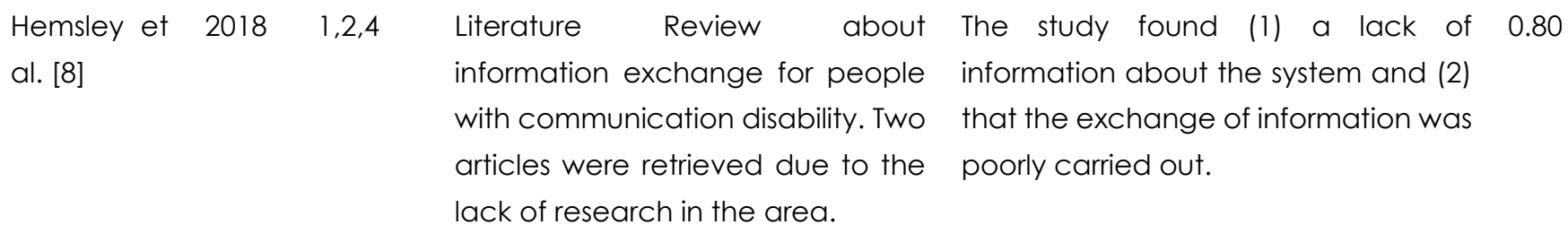

\begin{tabular}{lll}
\hline Kariotis et $2019 \quad 1,2,3 \quad$ & Qualitative descriptive study used \\
al. [15] & & in-depth semi-structured individual \\
& interviews from eleven participants \\
& in regional and remote areas of \\
& Tasmania to identify clinicians' \\
& perceptions about MyHR.
\end{tabular}

The study found that $100 \%$ (7) of the 0.87

General Practitioners' (GP) sample was aware of the MyHR System. However, only $71 \%$ (5) used it. The figure for psychologists was the opposite; none of the four was aware of the system and consequently did not use it. The main findings reflect two themes: (1) medication management, seen as helpful and (2) mental health information, expressing concerns about sharing sensitive material. Other concerns relate to the missing information shared by the patient, which might impact their treatment.

\begin{tabular}{llll}
\hline $\begin{array}{l}\text { Mendelson } \\
\text { et al. [16] }\end{array}$ & 1,2016 & Qualitative analysis of the My \\
& & Health Record Act 2012 (Cth) \\
& document covering legal and \\
& \\
& & \\
&
\end{tabular}

The objectives in the Act 2012 have 0.90 not been accomplished because (1) the health information accessed at the moment of consultation by the healthcare provider cannot be trusted once the system allows the owner of the information to change or remove data that could be vital without showing any trail or history to the healthcare provider, and (2) most private hospitals and specialists in private practice are not included in the system, which leads to information fragmentation.

\begin{tabular}{|c|c|c|c|}
\hline $\begin{array}{l}\text { Pearce et } \\
\text { al. [18] }\end{array}$ & 2014 & 2 & $\begin{array}{l}\text { Qualitative study about the design } \\
\text { and structure of the MyHR System } \\
\text { as at } 2014 \text {. }\end{array}$ \\
\hline
\end{tabular}

The most important findings from the research are (1) the Health Record Overview (MyHR website initial screen) shows relevant information, (2) clinical results are usually written using medical jargon, and health literacy levels vary in the population, which leads to incomprehension or misinterpretation of data, (3) information collected is not necessarily fit for sharing, and (5) 
veracity and completeness of information are contestable because the consumer can input wrong data or hide it.

\begin{tabular}{lll}
\hline $\begin{array}{l}\text { Van } \\
\text { Kasteren et }\end{array}$ & $4017 \quad \begin{array}{l}\text { Literature review included twelve } \\
\text { al. [21] }\end{array}$ \\
& articles about consumer \\
& perspectives on MyHR. Three \\
& papers collected data before the \\
& launch of the system, seven after \\
& the launch and one after the \\
& revision of the system. One study \\
& discussed digital medical records, \\
& not MyHR.
\end{tabular}

The literature review found low levels of awareness of and engagement with the system among individuals with chronic diseases, communication impairment and elderly patients; groups that would most benefit from the coordination of care.

Walsh et al. $2018 \quad 2,4$
[19]
Qualitative inductive analysis using 80 sources to analyse the quality of MyHR content from the consumer perspective.

\begin{abstract}
The study found (1) poor information readability for the public, (2) information was not targeted to priority groups, and (3) important information about how patients can engage with healthcare professionals was not provided.
\end{abstract}

\section{DISCUSSION}

The findings were organised into four themes, as illustrated in Table 6, and will be discussed in the same order: (1) health information fragmentation, (2) health information quality and access, (3) adverse medical event and duplication of treatment, and (4) coordination of care.

\section{HEALTH INFORMATION FRAGMENTATION}

Among the three authors [8, 15, 16], the findings were unanimous: the system has the potential to overcome the health information fragmentation identified in 2019 (date of the most recent research). However, there remain gaps. In Mendelson et al.'s[16] research conducted in 2016, it was stated that most private hospitals and specialists were not registered. As at 31 January 2019, the statistics from the MyHR website revealed that 186 private hospital organisations were registered of the total 630 existing private institutions [7, 22]. Therefore, only $29 \%$ of private hospitals were registered, supporting Mendelson et al.'s [16] finding.

Additionally, while GPs were aware of the system, only $71 \%$ used it. However, the author of this paper suggests that the trend of GPs usage has grown over time due to increased awareness of the system. Also, the figure for psychologists was exceptionally low, with all respondents reporting that they were not aware of the system and did not use it. Additionally, the concerns about sharing sensitive information on mental health are prominent among this group.

\section{HEALTH INFORMATION QUALITY AND ACCESS}

Several authors [8, 10, 15-19] in this area discussed both positive and negative issues of the system and information quality and access. The positive outcomes are that the health information stored in several repositories can be accessed by one system through an interface that shows relevant information on the first website page, which eliminates the reliance on patients remembering facts about their health during medical appointments. It also helps impaired and disabled people who might require help to gather their reports. Therefore, for this aspect, the system improves health information access. [8, 10, 17]

However, the use of that information requires caution. Three authors $[15,16,18]$ emphasised problems with the veracity and completeness of the data. Mainly, this viewpoint is based on two problems. Firstly, the patient can 
remove, hide or block access reports without doctors' approval. In this case, important information could be omitted and so lead to flawed decision-making. Secondly, patients can create notes and reports that might be incorrect, regardless of the patients' intention. The government also warns about this aspect. For medico-legal reasons, the change logs can be tracked if required and, in case of an emergency, GPs can override access and see essential data, but not the blocked information.

Another perspective is that not all patients have access to the MyHR (e.g., residents of aged care facilities) and, therefore, cannot review and update their information.[10] Additionally, some segments of the Australian community are unable to access and navigate the MyHR system (e.g., elderly citizens).[19] This inability could result in erroneous data that increases the likelihood of risk and harm.

Health literacy was also found to be a concern, with varying levels of knowledge related to the regions in Australia. [8, 18, 19] In addition to this, while the public might understand the system's language, minority groups might not. It was also identified that medical jargon could lead to misinterpretation of information, and not all data is fit for sharing, for example, laboratory results.

\section{ADVERSE MEDICAL EVENTS AND DUPLICATION OF TREATMENT}

While only two studies discussed this area, both have a robust SQAS score. However, the sample size (eleven [15] and twelve [10] participants) and the geographical area (regional Tasmania [15] and other regional areas of Australia [10]) does not allow for generalisation to the broader community. Overall, positive results were found. In the research conducted by Kariotis et al. [15], accessing patients' medication and other treatments record improved GPs' decision-making and avoided adverse medical events (e.g., drug interaction). In Hanna et al.'s [10] study, fewer duplication of investigations and appointments were experienced by patients because doctors could access their information from the MyHR system and see records of examinations and procedures undertaken in different facilities.

\section{COORDINATION OF CARE}

Four pieces of research were found in this area; two stated positive results and two stated negative results. It is noted that these papers are supported by contemporary, rigorous research. However, the findings contradict each other, and conclusions could not be drawn.
Almond et al. [20] state that the MyHR system supports person-centred and integrated healthcare, and that it works as an access point to more extensive healthcare provision. This system's outcome can positively affect the coordination of healthcare that involves a higher number of health professionals, prescribed medications, and healthcare costs, especially for patients who suffer complex chronic conditions. Van Kasteren et al. [21] also states that individuals with chronic diseases, communication disabilities, and older people would benefit most from the system. However, the author's literature review indicated that low levels of awareness and engagement were apparent among these group and the reasons may be in part attributable to poor engagement with and promotion of the MYHR by healthcare providers and services.

Hanna et al. [10] identified that the health providers' usage of the system assisted in coordination and improved healthcare due to the holistic and historic view presented by the system. The study also suggests an increase in patients' empowerment and interaction with physicians. However, Walsh et al. [19] analysed the content of the MyHR system and contradicted that finding. The authors hold the view that relevant information about how patients can engage with healthcare professionals was not provided.

\section{CONCLUSION}

The systematic literature review undertaken as part of this research article aimed to examine the progress of achieving the four objectives declared by the government in the MyHR Act 2012. While the system could reduce health information fragmentation, it still lacks the participation of most private hospitals and specialists.

The second significant finding was about health information access and quality. Although it was found that the MYHR system improved access to information, several problems were also identified. These variable levels of health literacy were found in different regions within Australia, [8, 18, 20] and while the general public might understand the system language, minority groups might not. It was also found that medical jargon could lead to misinterpretation of information, and therefore not all data is fit for sharing (e.g., laboratory results). 
There is limited research regarding adverse medical events and duplication of treatment. While two articles discussed positive outcomes in this area, they were located in remote areas of Tasmania and other regional areas of Australia. It would be premature to generalise these findings to the whole country. Contradictions in the research into the coordination of care were found. This prevented any clear conclusions being drawn.

Overall, the empirical findings in this study provide a perspective of the MyHR system and how much has been accomplished in the last seven years in relation to the objectives proposed. This study was limited to nine refereed pieces of literature, so it lacks deeper insight into each theme. More information on healthcare providers and patients' usage of the MyHR system would help to establish a higher degree of accuracy.

\section{FURTHER RESEARCH}

It was evident in this work that the four themes require further research. In relation to the health information fragmentation, it is suggested an investigation be conducted into the barriers faced by private hospitals and specialists and how to enhance their participation.

More information on MyHR users' and healthcare workers' experiences related to health information quality and access and management of care would help to establish a higher degree of accuracy on these matters. Another area for research may be understanding the barriers for patients and specific society segments accessing their MyHR (e.g., aged care residents). Further experimental investigations are needed to estimate the association between adverse medical events and duplication of treatment and the MyHR system.

\section{COMPETING INTERESTS}

The authors declare no conflicts of interest.

\section{FUNDING}

This research did not receive any specific funding.

\section{References}

1. Australian Government Department of Health. Personally Controlled Electronic Health Records for All Australians. Canberra: Department of Health; 2012. Available at:

http://www.health.gov.au/internet/budget/publishing .nsf/Content/budget2010-hmedia09.htm [verified 25 June 2019].

2. Australian Privacy Foundation. Value of My Health Record [Internet]. 2018. Available at: https://privacy.org.au/campaigns/myhr/value-ofmyhr/ [verified 25 June 2019].

3. Deloitte Touche Tohmatsu. Expected benefits of the national PCEHR system. 2012. Available at: http://tinyurl.com/y2e9aj5e [verified 25 June 2019].

4. Root J, Oster NV, Jackson SL, Mejilla R, Walker J, Elmore JG. Characteristics of Patients Who Report Confusion After Reading Their Primary Care Clinic Notes Online S. Health Commun. 2016;31 (6):778-81. DOI:10.1080/10410236.2014.990078.

5. Nohr C, Parv L, Kink P, Cummings E, Almond H, Norgaard JR, et al. Nationwide citizen access to their health data: analysing and comparing experiences in Denmark, Estonia and Australia. BMC Health Serv Res [Internet]. 2017; 17(1). DOI:10.1186/s12913-017-2482-y.

6. Fry CL, Spriggs M, Arnold M, Pearce C. Unresolved Ethical Challenges for the Australian Personally Controlled Electronic Health Record (PCEHR) System: Key Informant Interview Findings. AJOB Empirical Bioethics. 2014;5(4):30-6.

DOI:10.1080/23294515.2014.919972.

7. Australian Government. My Health Record Statistics [Internet]. In: Australian Digital Health Agency. Canberra: 2019. [Updated 2019 Jan 31; cited 2019 May 13] Available at: https://www.myhealthrecord.gov.au/statistics.

8. Hemsley B, McCarthy S, Adams N, Georgiou A, Hill $S$, Balandin S. Legal, ethical, and rights issues in the adoption and use of the "My Health Record" by people with communication disability in Australia. J Intellect Dev Disabil [Internet]. 2017: [1-9 pp.]. DOI:10.3109/13668250.2017.1294249.

9. Liyanage $\mathrm{H}$, Liaw S-T, Konstantara E, Mold F, Schreiber R, Kuziemsky $C$, et al. Benefit-risk of Patients' Online Access to their Medical Records: Consensus Exercise of an International Expert Group. Yearb Med Inform [Internet]. 2018. DOI:10.1055/s-0038-1641202. 
10. Hanna L, Gill SD, Newstead L, Hawkins M, Osborne $\mathrm{RH}$. Patient perspectives on a personally controlled electronic health record used in regional Australia: I can be like my own doctor. Health Information Management Journal [Internet]. 2017; 46(1):[42-8 pp.]. DOI:10.1177/1833358316661063.

11. Australian Government Department of Health. My Health Records Act 2012. Act No. 63 of 2012. Canberra: Department of Health; 2017. Available at: https://www.legislation.gov.au/Series/C2012A00063 [verified 25 June 2019].

12. Moher D, Liberati A, Tetzlaff J, Altman DG, Altman $D$, Antes $G$, et al. Preferred reporting items for systematic reviews and meta-analyses: The PRISMA statement. PLoS Med. 2009;6(7): e1000097. DOI:10.1371/journal.pmed.1000097.

13. Kmet L, Lee R, Cook L. Standard quality assessment criteria for evaluating primary research papers from a variety of fields. 2004. Edmonton: Alberta Heritage Foundation for Medical Research. 2011:1-22. DOl:https://doi.org/10.7939/R37M04F16.

14. Health Evidence. Quality Assessment Tool Review Articles. 2016. Available at: http://www.healthevidence.org/documents/ourappraisal-tools/QA_Tool\&Dictionary_10Nov16.pdf [verified 25 June 2019].

15. Kariotis TC, Harris KM. Clinician perceptions of My Health Record in mental health care: medication management and sharing mental health information. Aust J Prim Health. 2019;25(1):66-71.

DOl:http://dx.doi.org/10.1071/PY17181.

16. Mendelson D, Wolf G. "My [electronic] health record"-cui bono (for whose benefit)? J Law Med. 2016;24(2):283-96. Available at:

https://www.scopus.com/inward/record.urięeid=2s2.0-

$85049945158 \&$ partnerlD $=40 \&$ md5 $=150651 \mathrm{~b} 4 \mathrm{da} l \mathrm{e} 0629$ $4 a d 900$ ce00d7c832

17. Hemsley B, Georgiou A, Balandin S, Carter R, Hill S, Higgins I, et al. The Personally Controlled Electronic Health Record (PCEHR) for Adults with Severe Communication Impairments: Findings of Pilot Research. Stud Health Technol Inform. 2015; 214:100-6. DOI:10.3233/978-1-61499-558-6-100.

18. Pearce C, Bainbridge M. A personally controlled electronic health record for Australia. J Am Med Inform Assoc. 2014;21 (4):707-13. DOI:10.1136/amiajnl2013-002068.
19. Walsh L, Hill S, Allan M, Balandin S, Georgiou A, Higgins I, et al. A content analysis of the consumerfacing online information about my health record: Implications for increasing knowledge and awareness to facilitate uptake and use. Health Information Management Journal. 2018;47(3):106-15. DOI: $10.1177 / 1833358317712200$.

20. Almond $\mathrm{H}$, Cummings $\mathrm{E}$, Turner P. An Approach for Enhancing Adoption, Use and Utility of Shared Digital Health Records in Rural Australian Communities. Stud Health Technol Inform. 2017; 235:378-82. DOI:10.3233/978-1-61499-753-5-378.

21. Van Kasteren Y, Maeder A, Williams PA, Damarell

R. Consumer Perspectives on MyHealth Record: A Review. Stud Health Technol Inform. 2017; 239:146-52. DOI:10.3233/978-1-61499-783-2-146.

22. Australian Institute of Health and Welfare. Hospital resources 2015-16: Australian hospital statistics. 78 ed. Canberra: AlHW; 2017. p. 120. Available at: https://www.aihw.gov.au/reports/hospitals/hospitalresources-ahs-2015-16/contents/table-of-contents [verified 25 June 2019]. 